This session at AAAI also provided an opportunity to honor the team of Hans Berliner, Carl Ebeling, Murray Campbell and Gordon Goetsch for their work on the HITECH program at Carnegie-Mellon University. This program reached the peak of its development in 1988 when it consistently achieved a performance rating equivalent to that of a US Senior Master. The machine pioneered a custom VLSI chip, one for each square on the chess-board, allowing HITECH to search chess positions at a rate of 150,000 per second. HITECH's parallel processing capabilities were enhanced by a special pattern recognizer. Its major success was to be three-time Pennsylvania State Champion.

The second Fredkin Prize of $\$ 10,000$ was also awarded in 1988 , but to a rival group at Carnegie-Mellon University. The DEEP THOUght program built by Feng Hsu, Thomas Anantharaman, Murray Campbell, Andreas Nowatzyk and Mike Brown achieved a 2500 ELO rating, a level at which players tend to attain Grandmaster standing. DEEP THOUGHT might be considered to be BELLE on a VLSI chip, but with several chips working in parallel to search chess moves at a rate of 2 million positions per second. The notion of a singular extension was introduced by this group. Singularly good moves are extended to ensure that they remain safe. Anantharaman, the spokesman, gave an extensive discussion of DEEP THOUGHT's capabilities and made many claims about the ideas being developed at that time. The program was quite successful in individual games against Grandmasters, with wins and draws against many top players.

Finally came the grand prize, $\$ 100,000$ to Feng Hsu, Murray Campbell and Joe Hoane for DEEP BLUE. This machine, developed at IBM's Watson Research Laboratory, is the culmination of a major research and development effort, centered on Hsu's VLSI designs for a chess engine. Searching at a rate of 2 to 3 million positions per second per chip, and using 256 chips in groups of 8 on 32 RS-6000 workstations, this program had CPU-power to burn. Even so, its defeat of Garry Kasparov two months ago came as a surprise to many observers (including this one), who had anticipated that the World Champion would hold his own until the next decade. What we saw in the match was that the computer rarely wavered, and never gave up when the going got tough. The human side showed all the characteristics that one sees on the tennis court and by golf-players, it is hard to recover when things go wrong and it is difficult to play well when despondent. The carefully crafted and engineered piece of hardware and software that represents DEEP BLUE warms the heart of all technologists, and shows the world that perhaps computers can be relied upon to handle many more critical decision-making tasks! The session closed with promises that all the available literature about the DEEP BLUE project will be made available at IBM's web site as it is prepared. We can thus expect many additional disclosures over the coming months. The prospect for a re-match, however, is slim.

After the ritual photo session the pioneers broke into informal groups and stayed around to chat with the audience for some time. Only then did it dawn on the writer how much more could have been said on this occasion. From the presentations one is left with the impression that MIT and CMU were the primary source of pioneers in computer chess. To victors of course go the spoils, and in turn to write the history books. That the prizes were thoroughly earned is without question, but that many other things were necessary to make all this possible is also true. It was a pity that no mention at all was made of the many other developers of chess machines, for example Bob Hyatt and CRAY BLITZ, or the several European chess programmers - though perhaps their success has been too recent to warrant "pioneer" status. Still some recognition of those programmers who competed so vigorously in computer-chess events to keep the leaders on their toes and to force them to heights that they might not have achieved otherwise would have been appropriate. In particular, it would have been a generous gesture to mention the 25-years of ACM computer-chess events (from 1970 to 1994), and the work done by Monty Newborn to keep that great piece of experimental computer science alive long enough to help develop today's group of grandmaster-calibre chess programs.

\title{
CALENDAR OF COMPUTER-GAMES EVENTS 1997
}

\section{October 26-November 2, 1997}

The $15^{\text {th }}$ World Microcomputer Chess Championship, to be held in Paris, France. Details from David Levy, 89, Constantine Road, London NW3 2LP, England. Email: DavidL@intrsrch.demon.co.uk. See Vol. 20, No. 2, pp. 129-131, and this issue pp. 209-210.

November 22-23 and 29-30, 1997

The $17^{\text {th }}$ Open Dutch Computer-Chess Championship. Details from Theo van der Storm, Weth. Driessenstraat 5, 1107 XG AMSTERDAM Zuidoost. Email: tst@dasc.nl 